\title{
DOS MORTOS E SUA VOLTA: BIOGRAFIA E FAMÍLIA NA LITERATURA ESPÍRITA*
}

Sandra Jacqueline Stoll

Resumo: O propósito deste artigo é discutir representações sobre a morte a partir de produção narrativa gerada por meios mediúnicos. No universo religioso kardecista é corrente a ideia de continuidade da vida após a morte, tema largamente difundido por meio de sua literatura doutrinária. Dentre os vários gêneros utilizados para sua divulgação, o presente trabalho toma como objeto de análise a chamada "literatura de consolação", rótulo que designa "mensagens dos mortos", mediunicamente produzidas, tendo por finalidade o consolo de familiares. Sua circulação, sob a forma de livros, rompe o circuito privado, inserindo-as num mercado em expansão. Este é um rico material para se problematizar a noção de pessoa e biografia, bem como a noção espírita de família.

Palavras-chave: Espiritismo. Morte. Biografia. Família.

Abstract: This article aims to analyse representations on death in narratives produced by psychic practice. In Spiritist religious universe the idea of "after life" is current, subject wide spread out by means of it's doctrinal litterature. This work deals specifically with the so called "family messages", also labled as "comfort litterature". The publication of letters "written by the dead" breaks it's private circle, inserting them in a market in expansion. This is a rich data to discuss the concept of person and biography, as well as the spiritist notion of family.

Keywords: Spiritism. Death. Biography. Family.

A morte é um tema que vem se deslocando para o centro da reflexão sobre a sociedade contemporânea. Massacres, guerras, atos terroristas, práticas de genocídio e, também, desastres naturais são eventos que através dos meios de comunicação nos expõem cotidianamente à dor dos outros. Que impacto produz essa experiência?

É de senso comum a ideia de que a espetacularização da violência e da morte é responsável por sua banalização. Mas há quem sustente haver na superexposição

${ }^{*}$ Agradeço ao CNPq pelo financiamento dessa pesquisa.

${ }^{* *}$ Universidade Federal do Paraná. E-mail: sanstoll@terra.com.br 
a intenção de provocar reações. Susan Sontag (2003, p.16) defende essa posição: "De fato, há muitos usos para as inúmeras oportunidades oferecidas pela (forma) moderna de ver - à distância, por meio de fotografias - a dor de outras pessoas. Fotos de uma atrocidade podem suscitar reações opostas. Um apelo em favor da paz. Um clamor de vingança. Ou apenas a atordoada consciência, continuamente restabelecida pelas fotografias, de que coisas terríveis acontecem".

A condição de "espectador de calamidades", segundo a autora, é uma experiência tipicamente moderna. Esse "voyeurismo", afirma, Jean-Luc Nancy produz diferentes impactos segundo o tipo de condensação da imagem: há aquelas que saturam, que se esgotam em si mesmas; outras deixam espaço para o questionamento. Atribuindo às imagens do Holocausto esta última característica afirma: quando "o sofrimento do passado informa a experiência do presente, não se trata de dizer "que horror!", mas de indagar o que o tornou possível (...)". ${ }^{1}$

Na literatura antropológica, ainda é tênue a repercussão dessa discussão. Largamente inspirada em Ariès (1990), a produção etnográfica sobre a sociedade contemporânea tem se concentrado em reiterar a privatização como norma de conduta. Raros são os trabalhos que questionam essa visão, chamando atenção para a emergência de novas formas de experiência e inscrição da morte no espaço público.

O mesmo se observa com relação à produção da memória dos mortos. ${ }^{2}$ Em Tristes Trópicos, Lévi-Strauss se refere ao tema nos seguintes termos: "há sociedades que deixam os mortos em paz, abstendo-se de perturbá-los. Se voltam a vê-los, fá-lo-ão com intervalos e ocasiões previstas. E sua visita será benéfica, uma vez que os mortos garantem, pela sua proteção, o regresso regular das estações, a fecundidade dos campos e das mulheres". Outras sociedades, ao contrário, "recusam-lhes o descanso", mobilizando-os de várias formas: "às vezes literalmente, como é o caso do canibalismo e da necrofagia (com a) ambição de incorporar em si próprio as virtudes e poderes do defunto; ou então simbolicamente, (como é o

${ }^{1}$ Bimbuam, Jean - Máquinas de idolatria. Folha de São Paulo -São Paulo, 30 de janeiro de 2005, Caderno Mais! - tradução de Clara Allain, p. 2.

${ }^{2} \mathrm{O}$ único trabalho que trata do tema, que tenho notícia, é a coletânea organizada por Birman, Patrícia; Leite, Márcia. Um mural para a dor.movimentos político-religiosos por justiça e paz. Porto Alegre: Editora UFRGS, 2004. 
caso das) sociedades empenhadas em rivalidades de prestígio, nas quais os participantes (chamam) constantemente os mortos em seu auxílio, procurando justificar suas prerrogativas, por meio de evocações aos antepassados (...)”. Quanto à sociedade ocidental, Lévi-Strauss afirma que nesta "não há dúvida que a atitude especulativa se apagou progressivamente em benefício de uma relação contratual entre os vivos e os mortos, dando lugar a uma interferência anunciada talvez pela forma do Evangelho: deixem os mortos enterrar os mortos" (LÉVI-STRAUSS, 1975, p. 225-226).

É possível relativizar a generalidade dessa última afirmação, na medida em que se observa que a experiência do "recalcamento da morte" (CERTEAU, 1994; ELIAS, 2001), tida como atitude típica da sociedade ocidental a partir da modernidade, pode se manifestar de várias formas, inclusive pela intensificação da relação com os mortos como forma de negar sua condição de alteridade.

Da Matta (1987) explora essa possibilidade tomando como objeto de estudo a sociedade brasileira. Para apreender o seu modo particular de formulação da continuidade social entre vivos e mortos, o autor propõe um triângulo metodológico - a casa, a rua e o outro mundo -, por meio do qual, segundo ele, a sociedade brasileira opera o trânsito e a síntese entre espaços sociais, visões de mundo e éticas distintas de orientação social. ${ }^{3}$

A especificidade do modo brasileiro de lidar com os mortos é explorada pelo autor de forma mais sistemática no artigo "A morte nas sociedades relacionais: reflexões a partir do caso brasileiro" (DA MATTA, 1984). Neste se afirma que "a nossa noção de "alma" corresponde muito de perto a uma memória viva do morto, memória que vai ficando mais tênue na medida em que o tempo (...) passa (...) No caso do Brasil, pode até desaparecer a relação pessoal entre um

${ }^{3}$ De acordo com Da Matta, a casa, a rua e o outro mundo constituem "três perspectivas" de orientação de conduta e leitura da realidade, ou seja, "fazem mais do que separar contextos e configurar atitudes". Trata-se, diz o autor, de "visões de mundo ou éticas que são particulares (...) Não se trata de cenários ou máscaras que um sujeito usa (...) mas de esferas de sentidoque constituem a própria realidade e que permitem normalizar e moralizar o comportamento por meio de perspectivas próprias". Donde conclui o autor que "o comportamento esperado não é uma conduta única nos três espaços, mas um comportamento diferenciado, de acordo com o ponto de vista de cada uma das esferas de significação" (DA MATTA, 1984, p. 51-52, respectivamente; ênfase minha). 
dado morto e os seus sobreviventes e relações, mas não desaparece a relação complementar e compensatória entre o mundo dos mortos e o mundo dos vivos (...) é preciso não perder de vista que o "morto" é alguém que deixou o cenário (...) mas ainda mantém um elo potente com os que ficaram” (p. 169, 170, 172).

No presente trabalho pretendemos investir nessa direção, tomando o espiritismo como estudo de caso. A escolha se justifica por se tratar de doutrina religiosa cuja prática ritual se funda em múltiplas formas de produção do contato entre vivos e mortos. Estas práticas são frequentemente públicas, portanto, permitem investigar os modos pelos quais, nesse contexto particular, se criam formas coletivas de compartilhamento da experiência da morte e seus significados.

Dentre os vários meios utilizados pelos espíritas para a produção do contato entre vivos e mortos, privilegiamos um deles: a escrita. Dentre os vários gêneros, optamos pela chamada "literatura de consolação" - que reúne as "mensagens particulares", endereçadas "pelos mortos" a seus familiares. Produzidas em ritos públicos e difundidas por meio editorial, as "cartas espirituais" constituem um material inexplorado pela Antropologia, aqui privilegiado, pela possibilidade que oferece se problematizar a noção de biografia, bem como a representação espírita de família.

\section{A ESCRITA E A COMUNICAÇÃO COM OS MORTOS}

Como já observaram vários autores, a possibilidade de comunicação entre vivos e mortos se encontra enraizada na cultura religiosa brasileira. ${ }^{4} \mathrm{O}$ uso da escrita com esse fim não é, porém, corriqueiro.

No catolicismo, essa prática ocorre exclusivamente na comunicação com os santos, aos quais pedidos e agradecimentos são frequentemente endereçados. Estes, porém, são difíceis de serem registrados pois "raramente são enunciados em público" (MENESES, 2004). O contrário se observa com relação às graças recebidas, normalmente amplamente divulgadas, seja por meio dos ex-votos

\footnotetext{
${ }^{4}$ Da Matta (1987, p. 159) comenta esse respeito: "Vivemos num universo onde os vivos têm relações permanentes com os mortos e onde as almas voltam sistematicamente para pedir e ajudar, para dar lições de humildade cristã aos vivos, mostrando sua assustadora realidade".
} 
expostos no interior dos templos, seja através de "classificados" publicados em jornais diários ou, ainda, por meio da distribuição de "santinhos", impressos aos milheiros e disponibilizados em locais de grande afluxo de pessoas. Também as bênçãos e "milagres" se tornam públicos quando divulgados por meio de inscrições, em placas de metal, fixadas em locais votivos (grutas, capelas ao ar livre etc). ${ }^{5}$ Essa, porém, é uma forma de comunicação que se estabelece em situações especiais, em geral de crise pessoal.

Já no espiritismo, a comunicação com os mortos é prática ritual fundante da doutrina. Várias são as formas de comunicação utilizadas, todas elas realizadas por meio do transe mediúnico, sendo as mais conhecidas a escrita, a pintura, a oralidade e, também, as curas. Dentre estas, a escrita é considerada a principal forma de divulgação da doutrina. ${ }^{6}$ Sua prática se distingue daquela observada no catolicismo por uma inversão: enquanto no primeiro a escrita é um instrumento utilizado pelos vivos, no espiritismo. a escrita ritual é uma prática dos "mortos", realizada por meio de "médiuns".

A literatura espírita compreende um sem número de obras de divulgação doutrinária (romances, crônicas, poemas e outros), cuja autoria é atribuída aos "mortos". Nos últimos anos, esta vem ampliando seu espaço de divulgação editorial, como sugere reportagem da revista Época, de maio de 2003: "Tradicionalmente vendidos nos redutos kardecistas, os livros psicografados - escritos por pessoas que se dizem conectadas com almas que enviam mensagens do Além - (vêm despertando) a atenção das grandes editoras”. É o caso da Siciliano, uma das maiores do país, que, em meados de 2003, lançou o seu primeiro livro espírita, Do Outro Lado da Vida, de Arthur Vasconcelos: "sem divulgação, vendeu 10 mil exemplares em dois meses". A preferência do público por esse tipo de literatura é aquilatada como segue nesta mesma reportagem: "Hoje, um em cada dez

${ }^{5}$ Sobre esse tema, veja-se Birman, 1982.

6 "De todas as formas de comunicação, a escrita manual é a mais simples, mais cômoda e sobretudo a mais completa. (...) ela permite estabelecer relações permanentes e regulares com os Espíritos" In Kardec, Allan. O livro dos médiuns. 9a ed.São Paulo, LAKE, 1981, p.194.

${ }^{7}$ Cf. definição de Allan Kardec, o médium é aquele que "possui a faculdade sentir a influência dos Espíritos, traduzindo-a através de formas diversas de manifestação; escrita, pintura, oratória, etc" (idem, p.177). 
clientes entra em livrarias para comprar livros que trazem ditames enviados por espíritos". Uma pesquisa realizada no site Submarino confirma essa tendência: "o leitor espírita responde por mais da metade das encomendas de livros religiosos e compra $15 \%$ mais que os outros". Os campeões de venda nesse segmento são Allan Kardec, Chico Xavier, Zíbia Gasparetto ${ }^{8}$ e Vera Lúcia Marinzeck. No entanto, como observa o diretor-comercial do site Submarino, "pessoas de todas as crenças (consomem) esse tipo de obra", o que indica que a difusão dos preceitos doutrinários espíritas extrapola de longe suas fronteiras institucionais.

Um dos filões dessa produção editorial inexplorado até o momento pelos estudos antropológicos é a chamada "literatura de consolação", categoria que designa as publicações coletivas de "mensagens familiares". Produzidas em sessões públicas, por meios mediúnicos, algumas delas circulam sob a forma de panfletos, outras coligidas em livros. Fazendo da morte o ponto de partida da narrativa, estas reinventam não apenas a temporalidade, como a noção de vida com reverberações também na representação de família. São esses os temas tratados a seguir.

\section{"CORREIO DO ALÉM"}

A busca de notícias "dos mortos" é uma prática que semanalmente lota centros espíritas de diversas partes do país, em especial os centros espíritas de Uberaba/Minas Gerais, onde a prática da correspondência com os mortos se tornou a principal atividade das últimas décadas de atuação do médium mais famoso do país, Chico Xavier.

As sessões de psicografia no Grupo Espírita da Prece, lideradas por Chico Xavier, eram realizadas às sextas-feiras e sábados à noite, estendendo-se madrugada adentro. A fila era imensa, o número de senhas, porém, limitado a 60 . Chico Xavier mantinha uma conversa prévia com os inscritos, durante a qual fazia anotações. As informações básicas solicitadas eram: nome do falecido; nome do solicitante; data e causa mortis, nome do cônjuge, eventualmente (Chico Xavier/

\footnotetext{
${ }^{8}$ Há mais de 10 anos presente na lista dos mais vendidos, Zíbia Gasparetto é considerada atualmente "a mais popular escritora mediúnica". Outras informações sobre sua produção literária podem ser obtidas na edição de maio de 2003 da revista Época.
} 
Barbosa,1982:108-109; Souto Maior, 2004: 93). Esse mesmo procedimento idêntico é utilizado pelos demais médiuns que se dedicam a esta atividade.

A maioria daqueles que buscam "mensagens dos mortos" não são espíritas. Há registro disso na própria literatura em análise, como o depoimento que segue de um senhor que perdeu a esposa:

Nunca me ocorreu que receberia uma mensagem por escrito de minha falecida esposa. Não conhecia Chico Xavier pessoalmente, nunca (estivera) em Uberaba, e mais: não sou espírita. Em verdade você poderia me chamar de ateu, pois não acreditava em Deus. Mas como estava preocupado e triste resolvi ir a Uberaba. Tencionava procurar Chico (Xavier) para pedir notícias de minha mulher, para saber se ela estava bem, se precisava de alguma coisa - rezas, missas etc. (...) mas o fato é que eu estava do lado de fora, no galpão, conversando - e caçoando - com as pessoas que aguardavam notícias ou mensagens. (...) Eu duvidava da psicografia (...) Então como já estivesse tarde, resolvi ir embora. Foi quando ouvi alguém chamando meu nome. Esperei e quando me chamaram pela segunda vez, aproximei-me da porta onde estava (ocorrendo) a sessão (de psicografia) e perguntei: Moacyr de que? Quando deram o sobrenome vi que era eu mesmo. ${ }^{9}$

A divulgação das "mensagens familiares" por meio de folhetos distribuídos nos centros espíritas ou sua edição em livros, sob a forma de coletâneas, se difundiu largamente nas últimas décadas. Vários centros espíritas produzem suas próprias edições. Mais recentemente começaram a surgir publicações privadas - em caráter de homenagem -, empreendidas pela família do morto. Neste caso, em lugar de serem vendidos, os livros são distribuídos como presente.

Distinguindo-se de outros gêneros literários de divulgação da doutrina espírita, essa literatura é produzida numa relação direta com o público - mediador de sua produção e, também, consumidor imediato.

Conhecer detalhes do "evento derradeiro", assim como a preocupação com o bem-estar dos mortos constituem as principais motivações para a busca de "mensagens":

${ }^{9}$ Xavier, Chico/Barbosa, Elias/espíritos diversos. Quem são. São Paulo, Instituto de Difusão Espírita, 1982. p. 74 e 75 (excertos). 
“(...) Descobri os detalhes do assalto e o motivo da saída de casa (do meu filho) por meio de psicografias, pois somente (meses depois do ocorrido os) tais homens foram presos e confessaram o crime”, conta Deise Cassiolato. ${ }^{10}$

Alessandro Cassiolato (1998), o morto, relata o evento de sua morte como segue em sua primeira "mensagem":

Não sei ao certo o que se passou, fui abordado por dois homens, jovens ainda, que me renderam num assalto. Queriam o carro, não opus a eles nenhum obstáculo, de início.

Não esbocei qualquer reação que justificasse o que fizeram comigo. Apenas tentei escapar, porque não acreditei que me deixassem sair ileso daquela situação (...) Lamento (...) deveria ter ficado quieto, mas não é fácil ficar pensando no que pode nos acontecer, sem que esbocemos qualquer reação.

Não me queixo de ter perdido o corpo; recrimino-me, talvez, por não ter sabido preservá-lo por mais tempo (20/3/1997). ${ }^{11}$

Na terceira mensagem, outros detalhes do episódio são esclarecidos:

(...) naquela noite, quando entrei em casa pensando em descansar, senti fome. Depois de vasculhar a cozinha, tive a idéia de ir ao Habibs, em busca de um lanche rápido. Antes, porém, que descesse do carro, enquanto procurava estacionar, aconteceu tudo que vocês já sabem $(27 / 4 / 1997) .{ }^{12}$

Somente na sua oitava mensagem há referência às sensações físicas que envolveram o evento de sua morte. Estas são descritas de forma bastante genérica: "Não pensem que fiquei preso à dor: sentia que a cada minuto fugia de mim mesmo, até apagar de vez” (06/6/1997). ${ }^{13}$ Esse não é o padrão corrente. Quando

\footnotetext{
${ }^{10}$ Cassiolato, Deisy (org). Mensagens mediúnicas pelo espírito Alessandro Cassiolato. Maninha, estou bem. São Paulo, Edição do organizador, 1998.

${ }^{11}$ Idem, p. 30.

${ }^{12}$ Idem, p. 40.

${ }^{13}$ Idem, p. 50.
} 
a morte é produzida de forma súbita, inesperada e violenta, normalmente os relatos detalham as condições de produção do evento, assim como as sensações físicas e emocionais envolvidas na "experiência de passagem". É comum a referência a um torpor, sono e dificuldade de se movimentar. O processo de transição, porém, nem sempre é consciente.

Querida mãezinha Doralice (...) embora a dor nos pareça ter dado dias sem fim, estamos correndo as folhinhas da vida, (...) dia a dia contando a nossa saudade (...) Penso que não fui claro na minha primeira carta, em que não relatei o descuido do volante por (um) segundo e que não pude desfazer o descontrole da máquina, que caminhava dentro da outra pista e dentro daquela fração de segundos, ao voltar a atenção ao trânsito, já me encontrava prestes a bater contra o caminhão que vinha corretamente com seu motorista (...) Eu e o Fausto fomos envolvidos pelo susto rápido e batida forte me dopou todo o ser, de maneira a cair num profundo sono, que só veio clarear minha consciência dois dias depois que benfeitores me acolheram como se fossem familiares (...). ${ }^{14}$

Querida mamãe, ainda não posso escrever como desejo. O choque lembrado, ainda me paralisa as mãos. O Gregh, Ana Paula, Alessandra, com meu Gregh Jr., estão quase bons. Ainda estamos hospitalizados num tratamento rigoroso, pois a impressão de havermos sido cortados de um instante para outro ainda é muito difícil de suportar (Maria das Graças, 17/3/1979).

Na segunda mensagem, lê-se o que segue:

Descrever, mamãe, o que foi o choque dos veículos, quando nos aproximávamos daquele natal que se desfez em lágrimas, é muito difícil para sua filha. Creia que o Waldir fez tudo para que pudéssemos fugir ao caminhão enorme que se abeirava de nós. (...) de momento não tive certeza do que acontecia. Acredito que cheguei a gritar e a chamar por Deus, mas tudo foi uma questão de um pedaço de minuto. Não via mais (os filhos e) o esposo, porque uma energia esquisita me selou as pálpebras para um sono que não podia evitar. Foi um sono indescritível, porque me vi, como num pesadelo, arrastada para fora

${ }^{14}$ Afonso, Celso Almeida e Marques, Braz (médiuns)/ Espíritos diversos. Estamos vencendo. Uberaba/ Minas Gerais, Centro Espírita Aurélio Agostinho, 1998, p. 75. 
do turbilhão de destroços e acomodada numa grande maca, na idéia de que continuava no meu corpo físico". Conta ter tido um parto prematuro no além: "sentia-me fora do desastre (...) depois do sono de verdade, a criança repousava junto de mim (...) alguém se aproximou de mim (...) O espanto me tomou o coração. Quem me falava era a bisavó Carolina." (Maria das Graças, 17/5/ 1979). ${ }^{15}$

É comum a "conscientização da morte" associar-se ao reencontro com familiares já falecidos - em geral, os avós, no caso de crianças e jovens; pais ou cônjuges, no caso dos adultos. De modo geral, são estes que, de início, auxiliam a escrita das "mensagens":

"Querida mamãe, meu pai (...) Creiam vocês, a rapidez da escrita, o tipo de letra, em grande parte pertencem a eles, à Vovó Maria e ao nosso amigo Dr. Trajano, mas o que escrevo, o que passo nestas linhas (...) não é cola, nem sopro de outras inteligências" (Manoel Francisco Neto, 03/6/1977). ${ }^{16}$

"Alguém que passou por acontecimento difícil de descrever, que perdeu as forças (...), que ficou doente sem saber como e volta à família para dar notícias. Tenho a cabeça parecendo uma engrenagem enferrujada, com muito custo movendo as peças. É preciso pensar, embora o vovô Acyno esteja aqui comigo com a tia Raquel Bailão e outros protetores, quando da idéia de que me reajusto nos movimento mais por impulsão deles do que por minha própria capacidade (mas dizem) que as informações são necessárias (...) Que família conseguiria perder dois filhos de uma só vez e ficar imperturbável?" (Acylino Luiz Pereira Neto, 13/3/1976). ${ }^{17}$

Às vezes um membro da família falecido há mais tempo escreve no lugar do recém-falecido. Veja-se um exemplo:

${ }^{15}$ Idem, p.92, 93 e 94 (excertos).

${ }^{16}$ Xavier, Chico /Espíritos diversos. Correio do Além. São Paulo, Cultura Espírita, União,1983, p. 105.

${ }^{17}$ Mensagem originalmente publicada no Jornal Espírita, novembro de 1976, reproduzida na íntegra, com comentários de Elias Barbosa In:Xavier, Francisco/ Barbosa, Elias/ Espíritos diversos - Enxugando lágrimas. 24ª ed. São Paulo/Araras, IDE, 2004, p.49. 
"Querida filha Edna e estimado Eduardo (...) Edna, compreenda, minha filha, que o nosso Edu se encontra desnorteado com tudo que aconteceu a ele, horas atrás... Infelizmente eu e vários amigos da Vida Maior estamos tendo que nos esforçar muito para convencê-lo da realidade que ele ainda não aceitou (...) $\mathrm{O}$ nosso Edu ainda está se acreditando vítima de um pesadelo, porque ele próprio nunca teve a intenção de fazer o que fez. Esqueça quem lhe fale em suicídio, porque o nosso menino foi simplesmente vítima de sua própria invigilância e imaturidade. (...) O nosso Edu não está desamparado, apenas ainda confuso com tudo, tão confuso que sequer pude ainda me apresentar a ele na condição de avô (...)”. (Luiz Pires França). ${ }^{18}$

Quando a publicação reúne uma sequência de "cartas" de um mesmo "espírito" observam-se mudanças de ordem técnica, como a conquista de autonomia na escrita, e, também, no conteúdo das "mensagens". De início, a narrativa concentra-se na descrição do evento da própria morte como experiência de sofrimento em que o rompimento de laços afetivos se sobrepõe ao sofrimento físico. É recorrente a menção à tristeza e/ou revolta que, de início, envolve também aqueles que "passaram para o outro lado":

Querida mãezinha Acélia e querido papai Ulysses (...)

Quem está me auxiliando a escrever-lhes estas palavras é o meu bisâvo João Visconde, que está ao meu lado desde o infeliz acontecimento de dias atrás.

Eu não sei o que houve. Do que tenho permissão de dizer, lembro apenas que estávamos os quatro conversando... A conversa degenerou em discussão e uma faca apareceu na mão de um dos companheiros. Quis apartar a briga, temendo pelo pior. Um deles, o que seria esfaqueado, saiu correndo e deixou-me com os dois outros, que estavam, me parece, visivelmente drogados. Eu não sabia que eles usavam drogas. Senti apenas quando a lâmina começou a perfurar-me o corpo... Quis gritar por socorro, mas um deles me segurou os braços por trás, o outro cortou-me a garganta (...) Tenho o nome dos três na cabeça mas

${ }^{18}$ Bonilha, Pedro e Bacelli, Carlos (médiuns)/ Espíritos diversos. Aprendendo com a morte. São Paulo, Didier Editora, 2000 - p.58 e 59; excertos. 
os Espíritos Amigos aqui presentes não me permitiram denunciá-los, embora fosse meu desejo (...) (Ulysses Visconde Jr, 22/maio/1993). ${ }^{19}$

Na sequência, porém, os fatos tendem a ser reinterpretados. A experiência da separação, que de início é referenciada como "surpresa", "acidente" ou "evento inesperado" passa a ser relida como "desígnio". Revista da perspectiva moral, a vida definida como dívida engendra a morte, não como fim, mas como etapa de "resgate", como sugerem fragmentos de inúmeras dessas mensagens.

Ulisses, que no relato anterior conta como foi esfaqueado, numa segunda mensagem, psicografada pouco mais de um ano depois de sua morte, se dirige aos familiares como segue:

Lutemos para superar as lembranças amargas e coloquemos um ponto final nas discussões em casa (...) O que aconteceu comigo tem acontecido com milhares de pessoas no mundo, todos os dias... O sofrimento que bateu à nossa porta tem igualmente batido à porta de outros lares. Não se sintam vitimados, porque na realidade (...) todos somos mais algozes do que vítimas (...) (Ulysses Visconde Jr, 22/maio/1993). ${ }^{20}$

Minha mãe e meu pai! Recebam minhas palavras sem sombra de dúvida. Sei que não é fácil acreditar que nós, os mortos, possamos escrever aos vivos (...) Tenho me preocupado tanto com meus irmãos que não tenho cabeça para falar do acidente que sofri. Tudo tem sua razão de ser. Não pensem que eu estivesse sem o cinto de segurança por acaso. Quando o carro capotou, eu voei, batendo fatalmente a cabeça.

O que foi que eu fiz? Vocês querem de fato saber? Eu fui capitão-do-mato na época da escravidão, que com o faro dos cães procurava os escravos e, quando os encontrava, cortava-lhes os tendões. (...) Eu estive no Brasil no século passado. Ajudei a trazer para cá os escravos que aqui não conseguiam, no trabalho pesado, sobreviver mais do que 7 ou 8 anos. Foram cerca de 4000 escravos que morreram. Assumi pesado carma e outros assumiram também. Por isso os

\footnotetext{
19 idem, p. 50 .

${ }^{20}$ idem, p. 56.
} 
acidentes aparentemente inexplicáveis, tumores malignos, afogamentos, loucuras, os aviões que caem, dizimando dezenas de uma vez só... Fiz sofrer, sofri, estou sofrendo (...) Digo-lhes ainda que, quando voava do carro e na outra pista os veículos passavam por cima de mim, me vi, naquele exato momento, pisando inclemente na cabeça de nossos irmãos africanos. Muitos encontraram a morte sob minhas pesadas botas... (João Paulo M. Couto, natural de Portugal; Uberaba, 06/9/1997). ${ }^{21}$

Da percepção da morte como "resgate", segue a indicação da continuidade da vida como renovação de propósitos: estudos, trabalho, caridade.

Um ano, mais especificamente, treze meses. O tempo que vocês contam aí é assim, não é? Aqui é como um minuto diante de um turbilhão que se desenrola (...) Processos, reconhecimento, audiência, julgamentos, rotina necessária à lei material, porém a justiça divina é tão perfeita que, embora tudo aí deva seguir o curso previsto, por aqui os débitos e créditos são computadorizados de forma perfeita (...) Como vocês sabem, no início vovó me ciceroneou com muito carinho, mas aos poucos precisei me soltar e dar passos mais firmes e mostrar que aprendi a lição. Hoje, mais firme, digo a vocês: é hora de formarmos o Bloco do Trabalho. Eu aqui (com vovó, é claro) e vocês aí: temos condições de nos engajar em tarefas de auxílio a quantos nos solicitem (Alessandro Cassiolato, 04/2/1998; grifo meu). ${ }^{22}$

Entre meus colegas de partida muitas vezes repetíamos o slogan - "os jovens também morrem”. Por isso, de algum modo não me faltava preparação. Agora precisamos imprimir nova direção ao volante da vida. Reconhecer que existem outros (jovens) necessitados de socorro (...) Não estou fornecendo alguma de santo. Quero dizer que vou compreendendo a extensão da família extra-paredes. (...) Mamãe não pense com tanta dor a minha ausência. Novo dia aconteceu.

${ }^{21}$ Esta mensagem foi dirigida a uma tia do falecido, que se encontrava no Brasil e foi a Uberaba/ Minas Gerais, onde recebeu mensagem do sobrinho falecido há seis meses in: Bonilha, Pedro e Bacelli, Carlos (médiuns)/ Espíritos diversos - Aprendendo com a morte. São Paulo, Didier Editora, 2000, p. 82 e 83; excertos.

${ }^{22}$ Cassiolato, Deisy (org). Mensagens mediúnicas pelo espírito Alessandro Cassiolato - Maninha, estou bem. São Paulo, 1998. Edição do organizador - p. 73 e 74 excertos). 
(...) Temos muito a fazer e construir aqui e aí também. (Roberto. Garibaldo. Roberto de Salas, 10/8/1979). ${ }^{23}$

Lida como etapa da trajetória biográfica e não como seu fim, a morte deixa de ser vista como ruptura para ser reinterpretada como etapa de um percurso que se renova.

Concebida como ponto de intersecção, a morte se redefine como ponto de partida. A noção de continuidade implica espelhamento: o morto só tem identidade na relação com o próprio passado, que só existe como memória entre os indivíduos de suas ex-relações sociais mais próximas. Atualizá-las é, portanto, condição de construção de sua identidade como "presença”, que a escrita inscreve neste mundo, e a saudade perpetua para além deste, no tempo.

\section{A FIGURAÇÃO DO INVISÍVEL}

As regras que presidem a transcrição das "cartas espirituais" estão centralizadas no problema da recepção, isto é, envolvem critérios de organização que têm como alvo a questão da "autenticidade". Várias coletâneas consultadas apresentam fragmentos complementares de contextualização destas "mensagens" dos "mortos": foto seguida de uma rápida biografia do falecido, que inclui data e as circunstâncias de seu falecimento; ficha de identificação de nomes que ocorrem nas "mensagens" e, eventualmente, depoimentos de quem a recebeu. Algumas substituem este último por comentários relativos à doutrina espírita, contextualizados a partir de "destaques" selecionados no texto da "mensagem".

Certificar a autenticidade das "mensagens dos mortos" é uma questão inerente aos modos de sua produção como bem caracteriza Souto Maior: "se a escrita mediúnica de poemas, crônicas e romances é um terreno movediço, a psicografia de mensagens familiares é um terreno minado" (2004, p. 93).

A referência aos nomes de parentes vivos e mortos ou a forma "familiar" de se dirigir a eles, como apelidos; eventual reprodução de sua assinatura; a

${ }^{23}$ Xavier, Chico/Espíritos diversos. Estamosno Além. São Paulo/Araras, IDE, 1982, p.82. Ele assina "Garibaldo" como era popularmente conhecido cf. informação de familiares. 
publicização de certos fatos que não eram de conhecimento público, assim como a própria descrição das circunstâncias do evento que produziu sua morte, são "sinais indiciários" (GINZBURG, 1989) acionados na produção da verossimilhança.

Nem todos que recebem mensagens saem, contudo, convencidos ou mesmo consolados: "muitos desconfiam do conteúdo e do estilo das mensagens - repetitivas demais - ou se revoltam com o fato de não terem recebido noticias do além" (SOUTO MAIOR, 2004, p. 95). Há referências ao problema da dúvida em algumas mensagens:

Sei, desde a primeira carta, que me estranham o modo de falar através da escrita, mas é a visão dupla que me fez tudo de outra forma. Continuarei a luta para afastar a angústia que carrego, quando me lembro afastado de nossa casa, mas peço-lhes também não ficarem presos a negativismos que não me farão voltar. (...) Em não me tornei espírita, mas estou na condição de Espírito. A alma prossegue viva depois do impacto da morte do corpo, disto não posso fugir ( $3^{\mathrm{a}}$ carta de Irlo R. Galvão). ${ }^{24}$

Querida mãezinha Conceição e meu querido papai Indalécio (...) Estou presente nesta carta com as dificuldades em que me vejo para me retratar fielmente. Já que escrevo por outra mão, noto que a letra não pode assemelhar-se, de todo, à minha própria letra, mas escreve o com a alegria de quem achou um canal para afirmar-lhes que a morte não é senão certa mudança de lugar sem transformação de nós mesmos (Edílson, 12/6/1980). ${ }^{25}$

A mãe do rapaz conta o que segue num relato anexo a esta última mensagem:

Voltei de Uberaba e durante as 8 horas de viagem continuei abraçada com aquela mensagem em meu coração. Chegando em São Paulo, dei a mensagem para meu filho ler, e ele me disse: - Eu só vou acreditar no que está escrito aí

${ }^{24}$ Afonso, Celso de Almeida; Marques, José Braz (médiuns)/ Espíritos diversos. Estamos vencendo.Uberaba/Minas Gerais, Centro Espírita Aurelio Agostinho, 1998, p. 14 e 15 (excertos).

${ }^{25}$ Xavier, Chico e Barbosa, Elias/ Espíritos diversos. Quem são. São Paulo/Araras, IDE, 1982, p.136. 
se ele me chamar de irmão, como costumava me chamar. E ele começou a chorar ao ler a mensagem, pois nela (...) Edílson o chamava não pelo nome mas, sim, por irmão. ${ }^{26}$

(...) Que estas páginas que escrevo depois da morte não venham, depois de alguns meses, a amarelar, esquecidas no fundo de uma gaveta qualquer, como se fossem insuficientes para dar-lhes a certeza de que prossigo vivo". O detalhe desta psicografia, informa o comentarista, é o fato da assinatura ser a mesma que o comunicante possuía em vida (Esber Mikael Esber).

Ao contrário da narrativa ficcional, a biografia e a autobiografia, segundo Phillipe Lejeune (1996), têm como característica comum o fato de serem textos referenciais. da mesma forma que o discurso histórico ou científico, estas pretendem trazer informações sobre uma "realidade" que é exterior ao texto, podendo, portanto, ser submetidas a provas de verificação. Sua pretensão não é, portanto, a verossimilhança, mas o espelhamento do real; ou seja, o que se busca não é um "efeito de realidade", mas a imagem do real. Regidas pelo que o autor denomina de "pacto de referência", o real se apresenta nessas formas narrativas como produto do modo de sua enunciação.

Lejeune (1996) pensa essa questão à semelhança da discussão do "complexo xamanístico” em Lévi-Strauss (1975). Segundo o autor, os romances biográficos, assim como as autobiografias, são regidos por um "contrato de leitura", isto é, pelo compartilhamento de certas convenções entre o autor e seus leitores. Dentre estas, o autor destaca as normas de produção de identidade entre autor/narrador/ protagonista. Segundo Lejeune (1996), são convenções que diferenciam estas identidades nos textos em questão, a saber: 1) nas autobiografias autor/narrador/ protagonista estão ligados por um nome. Ou seja, a presença do autor no texto não se resume à assinatura do livro, mas remete a uma convenção social: o nome é o que identifica o autor (quem escreve e publica) a uma pessoa real (p. 23-24). Essa convenção Lejeune (1996) batizou de "pacto autobiográfico”. Segundo o autor este se distingue do "pacto romanesco", pois no romance biográfico não se supõe identidade entre autor e narrador. $\mathrm{O}$ atestado de "ficcionalidade" é dado por essa disjunção entre ambos.

${ }^{26}$ idem, p. 145. 
A ideia do "contrato de leitura" é fundamental para se pensar a inserção das "cartas espirituais" no "espaço biográfico", em que vigoram, segundo Lejeune (1996), diferentes formas de textualização do autor/narrador. Identificar os modos de "construção de si" implica, portanto, discutir um modo de leitura, assim como de escrita.

A leitura das "cartas espirituais" nos remete diretamente a esse jogo, na medida em que nestas são utilizados efeitos de realidade (nomes, apelidos, assinaturas etc), isto é, "sinais indiciários" (cf. GINZBURG, 1989) para a produção do espelhamento do real. Vista da perspectiva da morte, o vivo é uma sombra do morto. E vice-versa. Pensado como duplos, vivo e morto são distintos, porém sua alteridade fluida encontra no campo narrativo lugar de síntese: um é o outro. A narratividade tem, nesse caso, como sugere Certeau (1994), papel performativo: atualizando a presença dos ausentes, a escrita reconduz os mortos à convivência com os vivos, fazendo da produção de sua memória uma prática compartilhada.

\section{LAÇOS QUE (N)OS UNEM: FAMÍLIA E ESPIRITISMO}

A doutrina espírita, como se sabe, sustenta a continuidade entre vida e morte, concebendo-as como "planos de experiência" entre os quais os seres humanos alternadamente transitam, ligando-os, além da perspectiva temporal, os legados - que tanto presidem a construção das relações sociais, como a experiência individual. Ideia engendrada pela noção de $\mathrm{karma}^{27}$, entendida como algo que perdura e se renova no tempo.

Esses legadossão os fios que tecem as relações entre indivíduos. As "cartas espirituais" ilustram essa ideia sustentando que a morte, como a vida, é um universo em que se ingressa através de relações sociais. Os laços privilegiados pela doutrina são os laços familiares. Nas "cartas espirituais" essa representação se manifesta pela descrição da "passagem" entre a vida e a morte como transição da convivência com um segmento da família para outro - o dos vivos para o segmento dos familiares mortos:

\footnotetext{
${ }^{27}$ Popularmente a noção de karma se associa à ideia de provação, supostamente decorrente de débito(s) de vidas anteriores.
} 
Tudo, mamãe, foi muito rápido. Um choque difícil de descrever [...] a gente não se despede do corpo, sem antes desatar muitos laços e nem se desliga com muita facilidade do ambiente querido em que (desenvolvemos) a experiência familiar. (...) Senti-me perdida (...) era justo que eu te chamasse aos gritos [referindo-se à mãe] manifestando minha estranheza em altas vozes, mas quando vi o tio Orlando com aquele rosto sereno a fitar-me, ele que partira, antecedendo-me na Vida Espiritual, creio por onze meses, compreendi tudo (...) (assina Yolanda (Giglio Villela). ${ }^{28}$

Chegou aquele agosto difícil (...) Minha visão se ampliava no corpo a desmontar-se ou fora dele, vi-me ao lado da mamãe e da tia Nena (...) Voltei-me (...) e vi a tia Carminha sentada a me sorrir... Tia Carminha? A lucidez não me abandonara. (...) ela se ergueu e veio a mim dizendo: "Pedrinho, está com medo? Porque? Não nos conhece mais? (...) Então compreendi tudo e chorei muito..." E adiante acrescenta: "Agora já conheço outras pessoas queridas. A vovó Dolores, que se parece com a tia Carminha como se fossem irmãs gêmeas, a vovó Ana (...) (assina Pedro Luiz Galves). ${ }^{29}$

Intermediários entre os dois segmentos familiares, os recém-falecidos se tornam mediadores do reencontro de gerações. Em geral são pais e avós que "recebem" filhos e netos. Através desses recém-chegados, os familiares recebem "notícias" dos mortos mais antigos da família, como indicam os exemplos acima. No entanto, por vezes inverte-se a hierarquia geracional. Por exemplo, quando filhos "recebem" pais ou avós no "plano espiritual" e notificam sua "chegada" aos familiares.

Querida mãe Chiquinha, aqui se encontram amigos vários. Destaco, no entanto, a presença da vovó Josefina Cianflone, recentemente trazida para cá (...) A vovó, linda tal qual é, (...) não se compreende no diálogo comigo, tratandome como se estivéssemos nos tempos daí. Com a mais linda inocência me pergunta se estamos no Tatuapé (bairro da cidade de São Paulo) (...) porque a

${ }^{28}$ Mensagem recebida em 15 outubro de 1976, através do médium Francisco C. Xavier. EnXugando Lágrimas. 24a. edição. São Paulo/Araras, IDE, 2004, p. 19 e20.

${ }^{29}$ Mensagem psicografada pelo médium Francisco C. Xavier em 20 agosto 1982. Correio do Além. São Paulo, Editora Cultura Espírita União, 1983, p. 89. 
idéia de morte ainda não lhe alcançou a cabeça (...) O melhor de tudo é que devo conversar com ela sem alterar-lhe as idéias. Já confirmei que estamos no Tatuapé e ela me pediu hoje que me afastasse de motos. Maravilhosa vovó! Ela ignora que a moto já me promoveu a transferência... (assina Eduardo Ruiz Dellali). ${ }^{30}$

Mãe (...) Anteontem fui eu a rever meu pai. Ontem foi o velho Gregoris a retornar aos braços do filho. Meu avô que se fez de volta para cá, desconhecendo tantos fatos dos últimos tempos, surpreendeu-se muito ao reencontrar-me. "Véia", o seu dia chegará. Não se apresse (assina Henrique (Manuel Gregoris). ${ }^{31}$

A ideia do "reencontro", motivado por laços de afetividade, descreve um campo de relações sociais limitado em que os indivíduos gravitam na passagem entre a vida e a morte. Mas isso não significa um englobamento do indivíduo pela família. A ideologia individualista prevalece: tanto na vida terrena, como na vida post-mortem, a família não tem papel englobador. O indivíduo transita pela rede de relações familiares motivado pela busca de "desenvolvimento pessoal". Como outras redes sociais, a família é pensada como mediadora do processo de "aprimoramento pessoal", uma vez que, segundo a doutrina espírita, este se concretiza através da relação com o(s) outro(s).

O rompimento de laços também é compreendido como parte do processo. De início, porém, como se observa nos relatos, predomina a resistência a esse movimento.

Mamãe, é fácil morrer, mas não é fácil desencarnar. A pessoa continua tão profundamente ela própria que muita gente por aqui chega a não admitir (que) haja deixado a roupa física para envergar outros trajes. É uma graça e uma lástima (...) O Bernardo e eu continuamos juntos. Saímos para remar e continuamos remando de outro modo. Fomos acolhidos pela vovó Maria Celeste (...) Quando acordei por aqui, recolhendo o amparo que ela me proporcionou com meu avô Barros, o nosso encontro foi um tanto inamistoso. Ambos se esforçavam

${ }^{30}$ Mensagem psicografada pelo médium Francisco C. Xavier em 16 outubro 1982. Correio do Além. São Paulo, Editora Cultura Espírita União, 1983, p. 50.

${ }^{31}$ Mensagem recebida através do médium Chico Xavier. Publicada em OPopular (Goiânia, 18/7/ 1976. Enxugando Lágrimas. 24a. edição. São Paulo/Araras, IDE, 2004, p. 113 e 115. 
por enquadar-nos no conhecimento da morte; (mas) eu e o Bernardo reagimos contra. A vovó Celeste não pôde deixar de rir francamente quando lhe declarei que estava mais vivo do que nunca, que exigia meu barco e minha rede de volta a fim de regressarmos para a sua companhia e do papai Adalberto, do Junior e Maria Ângela, porque eu não encomendara morte nenhuma e o que eu queria mesmo, além do retorno à família, era me casar e ser feliz (...) Não sou infeliz, mas um tanto incorformado com aquele negócio de acidente (...) Não estou de cabeça nova, mas em outro corpo. Veja lá se isso é compreensível... (assina Ivo de Barros Correia de Menezes). ${ }^{32}$

O processo segue uma trajetória ritual. O passo seguinte consiste num reposicionamento perante os vivos, redefinindo-se papéis sociais. Parece que são os casos de conjugalidade aqueles em que o processo se manifesta mais claramente. Em alguns conjuntos de cartas atribuídas a um mesmo "autor espiritual” observa-se a proposição da reconfiguração familiar e, consequente, redefinição do lugar do morto como segue: 1) o morto "libera" o cônjuge para novas relações afetivas ou 2) ele próprio reconstrói laços afetivos e/ou familiares em "outro plano". ${ }^{33}$ Outra possibilidade é a transformação da relação conjugal numa relação de cunho fraterno, como se pode observar abaixo:

Querido Pretinho (Pintinho ?) (...) Não se detenha no quadro que a vida nos pede esquecer (...) Querido esposo, as nossas aspirações eram realmente muito grandes (...) Nossos sonhos se modificaram, mas nossa ligação espiritual é sempre a mesma (...) mas você está muito jovem para ficar sozinho. E aqui nossos sentimentos se ajustam à lógica. Se não posso continuar na posição de esposa, quem sabe? (...) reformulemos o caminho. É preciso um grande esforço para realizar essa química de transformação na vida interior, mas já fiz a que

${ }^{32}$ Mensagem psicografada, em 30/10/1982, em reunião pública, pelo médium Francisco C. Xavier. Retornaram contando. São Paulo/Araras, IDE, 1996, p. 51, 52 e 53 (excertos).

${ }^{33}$ Um exemplo: "[...] Além do trabalho (...) ocupo-me da minha vida pessoal e, do ponto de vista afetivo, devo dizer-lhes que estou enamorado de uma jovem desencarnada, pertencente a uma família tradicional de Osório; o nome dela é Carmem e estou imensamente feliz com o amor que descubro junto a ela (...)" assina: Edu (Eduardo Pischsenmeister Filho), mensagem psicografada, em sessão pública, pelo médium Carlos Bacelli, publicada em Aprendendo com a morte São Paulo/Votuporanga, Casa Editora Espírita “Pierre-Paul Didier”, outubro/2000, p. 115. 
me cabia efetuar (...) Amarei aquela que você encontrar (...) Tê-la-ei por filha, já que separada de você por forças da vida (...) (assina Viriginia Maria Sales de Oliveira). ${ }^{34}$

Por vezes essa reconstrução dos laços afetivos atinge também a relação entre pais e filhos, como se pode observar no exemplo abaixo:

A minha situação de pai-perto é boa por um lado, mas difícil de outro, (na medida em que) nem sempre consigo evitar que os entes amados venham a entrar em problemas e lutas de que necessitam para a aquisição de experiências, nas quais não devo e nem posso interferir (...) Acompanho cada filho quanto se me faz possível (...) depois da desencarnação (...) finalmente conseguimos examinar as pessoas conforme as necessidades que apresentam. Em vista disso, espero que me procurem sempre, no campo das recordações, na posição do amigo mais experiente e não do pai (...) (assina Waldemar Vieira). ${ }^{35}$

Renovando-se, portanto, de acordo com a doutrina espírita, conforme as "provas" que determinam "o tempo de cada um", a família é retratada no corpus documental em questão como unidade em constante redefinição. Os processos de segmentação e recomposição que governam a dinâmica familiar se desenvolvem no campo de tensão que marca, segundo Cavalcanti (1983), a trajetória dos indivíduos: de um lado, a doutrina espírita sustenta que estes têm poder de autodeterminação, o que se consigna na noção de "livre-arbítrio"; de outro, seus projetos e trajetórias são pensados como limitados por "desígnios divinos". A mesma tensão entre princípios contraditórios orienta a definição espírita da dinâmica familiar: os processos de segmentação e reunificação de seus membros não são controlados coletivamente, mas subjugados, de um lado, pelas "provas" a que os indivíduos se predispõem enfrentar; de outro, por uma lógica que lhe escapa (a "vontade divina").

A reconstituição da família é, portanto, um projeto. Sustenta-o a teoria da reencarnação, que conforme a versão espírita compreende a possibilidade de uma

${ }^{34}$ Mensagem psicografada em 15 de maio de 1982 pelo médium Francisco C. Xavier. Correio do Além. São Paulo, Editora Cultura Espírita União, 1983, p. 99, 100 e 101 (excertos).

${ }^{35}$ Mensagem psicografada, em sessão pública, pelo médium Francisco C. Xavier, em 21 de outubro 1979. Quem são. São Paulo/Araras, IDE, 1982, p. 45 e 46 (excertos). 
constante renovação das relações com base em afinidades pré-existentes e/ou construídas. A doutrina kardecista postula, no entanto, que certas relações familiares podem ter o caráter de "provação", ${ }^{36}$ mas esta face da família não aparece nas "cartas espirituais". A memória como reinvenção do passado desloca os conflitos para tempos remotos - outras vidas, outros tempos, outras relações. Dessa forma preserva-se, apesar das inflexões do tempo, a família como valor.

\section{REFERÊNCIAS}

BIRMAN, Patrícia. Modos periféricos de crença In: Sanchis, Pierre (org.) Catolicismo: unidade religiosa e pluralismo cultural. São Paulo: Loyola. 1992 BOURDIEU, Pierre. A Ilusão Biográfica In: Razões Práticas. Sobre a teoria da ação. São Paulo/Campinas: Papirus, 2001.

CAVALCANTI, Maria Laura V. O mundo invisível. Cosmologia, sistema ritual e noção de pessoa no espiritismo. Rio de Janeiro: Zahar, 1983;

CERTEAU, Michel De. A escrita da história. Rio de Janeiro, Forense Universitária, 1994.

DA MATTA, Roberto. A casa e a rua. Rio de Janeiro: Editora Guanabara, 1984.

ELIAS, Norbert. A solidão dos moribundos. Rio de Janeiro: Jorge Zahar, 2001.

GINZBURG, Carlo. Mitos, emblemas e sinais. São Paulo: Companhia das Letras, 1989.

${ }^{36}$ Em O evangelho segundo o espiritismo, de Allan Kardec, lê-se a esse respeito: "a união e a afeição que existem entre parentes são indício de simpatia anterior que os aproximou. Por isso, falandose duma pessoa cujo caráter, gostos e inclinações não têm nenhuma semelhança com os parentes, diz-se que ela não pertence à família. Assim dizendo-se, enuncia-se uma verdade maior do que se imagina. Deus permite nas famílias essas encarnações de espíritos antipáticos ou estranhos, com a dupla finalidade de servirem de prova para uns e meio de progresso para outros. Então os maus melhoram pouco a pouco ao contato com os bons, pelos cuidados que recebem. Seu caráter se abranda, seus costumes depuram, as antipatias se desfazem. É assim que se estabelece a fusão entre diferentes categorias de espíritos, como acontece na Terra entre raças e povos" . São Paulo, FESP, 1982, p. 82 
LEJEUNE, Philippe. Le pacte autobiographique. Paris, Éditions du Seuil, 1996 [1975].

LÉVI-STRAUSS, Claude. Antropologia estrutural. Rio de Janeiro: Tempo Brasileiro, 1975.

LÉVI-STRAUSS, Claude. Tristes trópicos. Lisboa: Presença, 1986.

MENESES, Renata de C. Saber pedir: a etiqueta do pedido aos santos. Religião e Sociedade 24/1. Rio de Janeiro: ISER, 2004.

SONTAG, Susan. Diante da dor dos outros. São Paulo: Companhia das Letras, 2003.

\section{LITERATURA ESPÍRITA}

AFONSO, Celso de Almeida; Marques, José Braz (médiuns)/ Espíritos diversos. Estamos vencendo. Uberaba/Minas Gerais, Centro Espírita Aurelio Agostinho, 1998.

BONILHA, Pedro e Bacelli, Carlos (médiuns)/ Espíritos diversos. Aprendendo com a morte. São Paulo, Didier Editora, 2000.

CASSIOLATO, Deisy (org). Mensagens mediúnicas pelo espírito Alessandro Cassiolato. Maninha, estou bem. São Paulo. Edição do organizador, 1998.

KARDEC, Allan. O evangelho segundo o espiritismo. São Paulo: FESP, 1982.

XAVIER, Chico; Barbosa, Elias. Espíritos diversos. Quem são. São Paulo/Araras, IDE, 1982

XAVIER, Francisco; Arantes, Hércio. Espíritos diversos. Eles voltaram. São Paulo/Araras, IDE, 1981.

XAVIER, Francisco Candido. Espíritos diversos. Estamos no Além. São Paulo/ Araras, IDE, 1982.

XAVIER, Francisco Candido. Espíritos diversos. Correio do Além. São Paulo, Cultura Espírita União, 1983. 
XAVIER, Francisco Candido. Espíritos diversos. Enxugando Lágrimas. 24a. edição. São Paulo/Araras, IDE, 2004.

XAVIER, Francisco Candido. Espíritos diversos. Retornaram contando. São Paulo/ Araras, IDE, 1996. 